\title{
Using Apps in Formal Education to Improve Executive Functions in Preschoolers
}

\author{
Sabrina Panesia, Lucia Ferlino ${ }^{a}$ \\ ${ }^{a}$ National Research Council of Italy, Institute for Educational Technology, Genoa, Italy, \\ panesi@itd.cnr.it, ferlino@itd.cnr.it
}

\begin{abstract}
The term Executive Functions (EFs) refers to a set of higher order cognitive processes that are critical for goal directed behaviour. They include inhibition (i.e., the ability to suppress task-irrelevant cognitive processing and ignore salient yet irrelevant features of the situation), shifting (i.e. the ability to switch between different operations or levels of processing), and updating (i.e. the ability to encode, hold and monitor incoming information in working memory, replacing information that is no longer relevant with new information). The most notable developmental change in children's EFs occurs during the preschool period, and this is associable to and predictive of children's general learning ability. For this reason, efforts to develop EFs in preschoolers is of vital importance. In recent years, only few studies have investigated the effect of EFs intervention on preschoolers, despite the potential preventive effect of early intervention on later developmental problems. A number of related solutions have been proposed over the years, including both paper-and-pencil activities and digital applications (e.g., software and videogames). However, few attempt have been made to integrate the many advantages of traditional, low-cost playful activities with the (often) powerful affordances of digital technologies. Hence, we propose just such a hybrid solution, with a set of mobile applications (apps) designed to foster EF development among early learners in education settings. We opted for such a solution as mobile apps have proved to be familiar, highly usable and well accepted among young children. At a more general level, this contribution seeks to provide useful input on the affordances and indicators that can help guide the effective choice of apps useful for developing EFs, and how these tools can be optimally introduced and employed in traditional teaching and learning programs.
\end{abstract}

Keywords: executive functions, app, preschoolers, educational context 


\section{Introduction}

Executive Functions (EFs) refer to a family of adaptive, goal-directed, top-down mental processes needed to focus and pay attention and when an automatic response would be insufficient (e.g., Burgess \& Simons, 2005). There is general agreement that three core EFs exist (Miyake, Friedman, Emerson, Witzki, Howerter, \& Wager, 2000; Miyake \& Friedman, 2012): (a) inhibition, namely the ability to suppress task-irrelevant cognitive processing and ignore salient yet irrelevant features of the situation; (b) shifting, namely the ability to switch between different operations or levels of processing; and (c) updating, namely the ability to encode, hold and monitor incoming information in working memory, replacing information that is with new information.

Furthermore, Miyake et al. (2000) suggest the possibility that all EFs rely to some extent on Working Memory (WM), i.e. the simultaneous maintenance and manipulation of information.

Although EFs develops over a long period spanning the first year of life until late adolescence, the most remarkable change in EFs skills occurs during the preschool period ${ }^{1}$ (e.g., Garon Bryson, \& Smith, 2008; Morra, Panesi, Traverso, \& Usai, 2018). There are studies demonstrating that the development of EFs and WM in this period is associable to and predictive of children's general learning ability, such as mathematical achievement (e.g., Blair, \& Razza, 2007; Clark, Pritchard, \& Woodward, 2010) and literacy ability (e.g., Blair, \& Razza, 2007). For this reason, efforts to improve WM and EFs in preschoolers are of vital importance as a prevention strategy, in particular for children with a potential delay or impairment in the development of EFs, such as children at risk of acquiring ADHD symptoms (e.g., Re, Capodieci, Cornoldi, 2015), children with specific language impairment (e.g., Vissers, Koolen, Hermans, Scheper, Knoors), or children whose development is impeded by their low socio-economic backgrounds (e.g., Miech, Essex, \& Goldsmith, 2001). In this regard, there are studies demonstrating that EFs can be improved in preschoolers in regular classrooms and the benefits are transferrable to other activities (e.g., Diamond, Barnett, Thomas, Munro, 2007). Therefore, school teachers could play a crucial role in supporting children's development of WM and EFs (e.g. Bodrova \& Leong, 1996) by providing challenging activities performed in suitably designed environments

\footnotetext{
1

The structure of EFs and WM in this period is controversial: some studies (e.g., Wiebe, Scheffield, Nelson, Clark, Chevalier, Espy, 2011) propose a single factor for all executive functioning while others (e.g., Miller, Giesbrecht, Muller, McInerney, Kerns, 2012). propose two factors. This doubt makes it difficult to distinguish the main EFs (inhibition, shifting and updating) and WM in preschoolers.
} 
(e.g., Traverso, Viterbori, \& Usai, 2015; Passolunghi \& Costa, 2016) that blend paper-andpencil enviroments with the new technologies young digital natives find so attractive (e.g., Dini \& Ferlino, 2016).

Based on a review of the literature, the main aims of this paper are to:

(1) provide a theoretical deepening about the importance of integrating technological tools in traditional educational programs to improve EFs and WM in preschoolers, focusing in particular on the powerful affordances of educational apps;

(2) provide suggestions for selecting and evaluating apps useful for promoting EFs and WM in the educational context;

(3) provide practical information about how teachers can use apps to improve WM and EFs, integrating their use with traditional educational activities.

\section{Integrating Technological tools to improve EFs and WM in the educational context}

WM and EFs interventions using digital applications (e.g., software or video games) have the dual advantage of automatically modifying task difficulty according to performance and focusing on specific EF components. However, these programs are rarely generalizable to daily life activities and are resource consuming, requiring individual exercises and extensive teacher training (e.g. Rueda, Checa, \& Combita, 2012; Thorell, Lindqvist, Bergman Nutley, Bohlin, \& Klingberg, 2009). To avoid these problems, Di Lieto and colleagues (2017) propose altenative activities based on Educational Robotics that stimulate children to maintain and update information, inhibit automatic response and solve problems. These researchers argue that Educational Robotics allow children to integrate several EF training strengths, such as: a) incremental challenging tasks based on an adaptive paradigm, b) real engaging objects to work on, and c) group settings.

Though partially effective, EF training programs using technologies for preschool children can be challenging and expensive when applied in standard educational contexts. On the other hand, EF training programs based on low-cost paper-and-pencil activities can be costeffective but clash with the drive for digitally-based school innovation. Furthermore, while digital-based EF training programs tend to favour individual activities, those adopting paper-and-pencil activities tend to favour small group activities.

Clearly, the space exists for a mixed method that integrates digital approaches with more traditional, low-tech activities. A key advantage of this method would be useful for 
combining the development of EFs on an individual basis with digital activities with EF improvement through more traditional group activities.

To this end, we need to identify a digital solution appropriate for employing in a mixed method. We maintain that mobile applications (apps), in particular educational apps, can represent a valid tool to foster EF development among early learners in education settings.

\section{Powerful affordances of Educational Apps}

The term educational app refers to a software application designed to support learning (e..g, Bouck, Satsangi, \& Flanagan, 2016) that works on a mobile device (Purcell, Entner, \& Henderson, 2010) such as tablet or smartphone. These devices are available to practically everyone, including young children (Holloway, Green, \& Livingstone, 2013). In particular, Hirsh-Pasek and colleagues (Hirsh-Pasek, Zosh, Golinkoff, Gray, Robb, \& Kaufman, 2015) argue that educational apps are those designed to promote active, engaged, meaningful, and socially interactive learning within the context of a supported learning goal.

Despite the potential and increasing uptake of apps, there is limited understanding of their impact on young children's learning and development. In particular, there is limited understanding of how apps can improve the cognitive development of young children. In this regard, Huber and colleagues (2018) found that apps can play an important role. Specifically, these authors studied 2- and 3-year-old children's experience of three different screen-based interventions: watching an educational television show; playing an educational $\mathrm{app}^{2}$; and watching a cartoon. It emerged that children's WM improved after playing the educational app.

The tactile-based interface of touchscreens enables the introduction of digital interaction at an early age (Plowman, Stevenson, Stephen, \& McPake, 2012; Dini, Ferlino, 2016). Young children instinctively touch the screen and experience objects that appear as if they were real. Preschoolers think it is normal to receive feedback when they touch the screen, assuming that everything around them is interactive and responsive to the same gestures they use to interact with tablets (Dini, \& Ferlino, 2016). This near-direct relationship with what appears on the screen and the mind-set that virtual objects react according to the type

2

In this study, the authors use the app Shiny Party by the developer Shiny Things. It was chosen for the opportunities it offers to learn shapes and complete puzzles, activities set within the narrative of preparing for a character's birthday. The app can be considered educational in that it incorporates a learning goal [Hirsh-Pasek et al., 2015]) and features a physically interactive dimension accessible to the age of users (Huber et al., 2018, p.76). 
of touch are factors underlying the attractiveness and increasing success of apps for mobile devices (Kopecký \& Szotkowski, 2015).

These features make apps used via mobile devices more approachable for young children than software used on the computer. Other comparative advantages include lightweight design, portability, relatively intuitive interfaces, communication features, and affordability (e.g., Vavoula \& Karagiannidis, 2005). Finally, young children are often gain familiarity with apps proposed to them by their parents for leisure purposes (Dini, \& Ferlino, 2016).

\section{Suggestions for selecting and evaluating apps}

Teachers who decide to propose apps to preschoolers with the aim of promoting EFs and WM need to be aware that no single app exists that has been designed to develop one cognitive ability in isolation. Some, however, promote multiple cognitive abilities simultaneously, as is the case with traditional playful paper-and-pencil activities created for training preschoolers (e.g., Traverso et al., 2015).

A typical example is a memory game app that invites players to (a) pay attention to the moves of the virtual player (the opponent), (b) memorise the visual information, (c) recall necessary information at the right time, and (d) inhibit unnecessary information.

This multiplicity of WM and EFs addressed is but one of the key characteristics teachers need to consider when selecting apps for educational use by preschoolers. First, according to traditional WM and EF training approaches (e.g., Traverso et al., 2015; Caponi, Clama, Re, Cornoldi, e gruppo docenti "Rete Ricerca infanzia" di Treviso, 2009) apps must propose activities graduated in difficulty "from the simplest to the most complex". They can also offer added value by proposing activities that are calibrated in response to the performance of the young user; that is, children can start from an easy level and progress to increasingly complex levels based on their individual performance. This helps to optimise the level of challenge, which is key to both motivation and successful performance. Another key to motivation in young children is the level of fun the app induces. Furthermore, apps need to provide feedback so that the young user gains a sense of their performance and progress.

Selecting effective apps for preschoolers also involves some key technical elements (a) clear, well defined contents; (b) attractive graphics and design; (c) audio-visual rather than text-based communication; (d) effective exploitation of touchscreen interaction; (e) limited screen size; (f) active/touch-sensitive screen areas of sufficient size (Dini, \& Ferlino, 2016). A good example of the role these elements play in an app for improving preschoolers' EFs 
and WM is "A Memory Game for Kids" ${ }^{3}$ by Rony Arbiv. This app proposes four fun and original games to improve different memory skills and responds well to the six technical criteria mentioned above. Figure 1 shows the "auditory memory game". This activity proposes a "span task" in which children must memorise and process an increasing quantity of auditory information and provide a simple motor response (touch the screen). Specifically, the child listens to the individual sounds from a series of onscreen monsters; then, an off-screen speaker reproduces one of those sounds. The child must identify the monster that produced that sound by touching it. If the child responds correctly, the number of sounds produced by monsters increases but if the child makes a mistake, the number of sounds decreases.

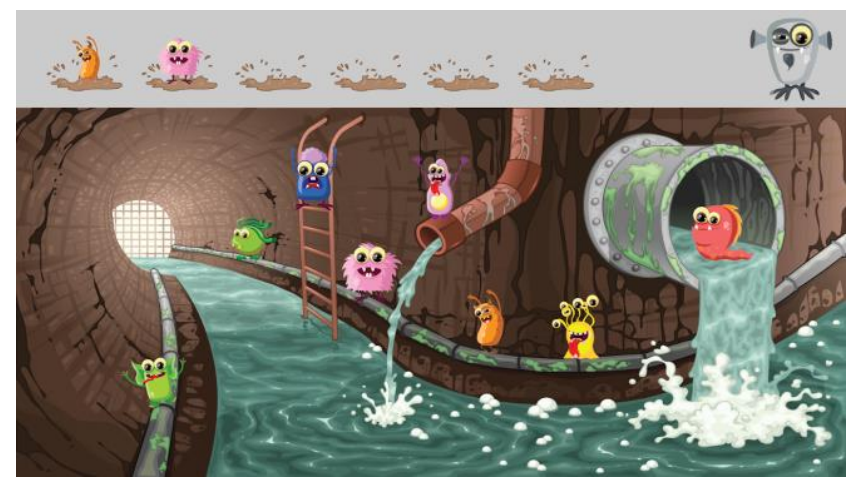

Fig 1. Screenshot of the app "A memory app for kids", activity "auditory memory game" Source: https://itunes.apple.com/it/app/a-memory-game-for-kids/id1070495677?mt=8 or https://play.google.com/store/apps/details?id=air.com.shubi.memoryEnglish\&hl=it

\section{How teachers can use apps to improve WM and EFs}

Using only apps to improve preschoolers' EFs and WM would be limiting; it is fundamental to integrate app use with traditional educational activities, ideally fun activities carried out in small groups. Clearly, the cognitive abilities targeted by the app and the group activity should match. When the individual and group activities are concluded, the teacher can help the children reflect about the strategies they used to tackle the tasks, the

3 Link (iOS): https://itunes.apple.com/it/app/a-memory-game-for-kids/id1070495677?mt=8

Link (Android): https://play.google.com/store/apps/details?id=air.com.shubi.memoryEnglish\&hl=it 
difficulties they faced, and how they overcame them. Such collective teacher-mediated reflection can foster metacognitive abilities, even in quite young children.

To obtain an effective outcome, it is fundamental to plan a learning path that (a) comprises a series of sessions in which activities of increasing difficulty are proposed, and (b) alternates individual app games with more traditional non-digital group games. Additionally, the learning path must be flexible enough to allow modification according to the (emergent) needs of the children.

\section{Conclusions}

Improving EFs and WM in pre-schoolers is of vital importance because they are associable to and predictive of children's general learning ability. School teachers could play a crucial role in supporting the development of WM and EFs in the educational context, proposing integrated educational programs that include both paper-and-pencil and technological activities. In the latter case, educational apps, if appropriately selected and evaluated, seem to offer a series of features that are useful for promoting pre-schoolers' WM and EFs. Therefore, suggestions for selecting and evaluating apps provide fundamental support to teachers who are seeking to promote $\mathrm{WM}$ and EFs in young children.

\section{Acknowledgments}

Special thanks to Jeffrey Earp for linguistic revision.

\section{References}

Bouck, E.C., Satsangi, R., Flanagan, S. (2016). Focus on inclusive education: Evaluating apps for students with disabilities: supporting academic access and success. Childhood Education, 92(2), 324-328.

Blair, C., Razza, P. C. (2007). Relating effortful control, executive function, and false belief understanding to emerging math and literacy ability in kindergarten. Child Development, 78, 647-663.

Bodrova, E., and Leong, D. J. (1996). Tools of the Mind: The Vygotskian Approach to Early Childhood Education. Englewood Cliffs, NJ: Merrill/Prentice Hall. 
Burgess, P. W., \& Simons, J. S. (2005). 18 theories of frontal lobe executive function: Clinical applications. The effectiveness of rehabilitation for cognitive deficits. New York: Oxford Univ. Press.

Caponi, B., Clama, L., Re, A.M, Cornoldi, C., e gruppo docenti "Rete Ricerca infanzia" di Treviso (2009). Sviluppare la concentrazione e l'autoregolazione. Giochi e attività sul controllo della memoria di lavoro - Vol 3. Trento: Erickson

Clark, C. A. C., Pritchard, V. E., and Woodward, L. J. (2010). Preschool executive functioning abilities predict early mathematics achievement. Developmental Psychology, 46, 1176-1191.

Diamond, A., Barnett, W.S., Thomas, J., Munro, S. (2007). Preschool program improves cognitive control. Science, 318, 1387-1388.

Di Lieto, M.C., Inguaggiato E., Castro E., Cecchi F., Cioni G., Dell'Omo M., Laschi C., Pecini, C., Santerini, G., Sgandurra, G., Dario P. (2017). Educational Robotics intervention on Executive Functions in preschool children: A pilot study. Computers in Human Behavior, 71, 16-2.3

Dini, S., Ferlino, L. (2016). Knowledge at their fingertips: kids' learning and playing in the app age. TD Tecnologie Didattiche, 24(3), 147-155.

Garon, N., Bryson, S. E., \& Smith, I. M. (2008). Executive function in preschoolers: a review using an integrative framework. Psychological Bulletin, 134(1), 31-60.

Huber, H, Yeates, M., Meyer, D., Fleckhammer, L., Kaufman, J. (2018). The effects of screen media content on young children's executive functioning. Journal of Experimental Child Psychology, 170, 72-85

Hirsh-Pasek, K., Zosh, J. M., Golinkoff, R. M., Gray, J. H., Robb, M. B., \& Kaufman, J. (2015). Putting education in "educational” apps: Lessons from the science of learning.

Psychological Science in the Public Interest, 16, 3-34.

Holloway, D., Green, L., \& Livingstone, S. (2013). Zero to eight: Young children and their internet use. EU Kids online. London. Retrieved from http://eprints.lse.ac.uk/52630/1/Zero to eight.pdf

Kopecký, K., \& Szotkowski, R. (2015). Use of mobile touch devices as part of lifelong learning with specific focus on tablets. Proceedings of ICLEL 2015 - International Conference on Lifelong Education and Leadership, 221-225

Miech, R., Essex, M. J., \& Goldsmith, H. H. (2001). Socioeconomic status and the adjustment to school: The role of self-regulation during early childhood. Sociology of Education, 74(2), 102-120.

Miller, M. R., Giesbrecht, G. F., Muller, U., McInerney, R. J., \& Kerns, K. A. (2012). A latent variable approach to determining the structure of executive function in preschool children. Journal of cognition and development, 395-423. 
Miyake, A., Friedman, N. P., Emerson, M.J., Witzki, A.H., Howerter A., \& Wager, T.D. (2000). The unity and diversity of executive functions and their contributions to complex "Frontal Lobe" tasks: a latent variable analysis. Cognitive Psychology, 41(1), 49-100.

Miyake, A., \& Friedman, N. P. (2012). The nature and organization of individual differences in executive functions: four general conclusions. Psychological Science, 8-14.

Morra, S., Panesi, S., Traverso, L., Usai, M.C. (2018). Which tasks measure what? Reflections on executive function development and a commentary on Podjarny, Kamawar, and Andrews (2017). Journal of Experimental Child Psychology, 167, 246-258.

Passolunghi, M.C., Costa, H.M. (2016). Working memory and early numeracy training in preschool children, Child Neuropsychology, 22:1, 81-98.

Plowman, L., Stevenson, O., Stephen, C., \& McPake, J. (2012). Preschool children's learning with technology at home. Computers \& Education, 59(1), 30-37.

Purcell, K., Entner, R. and Henderson, N. (2010) The Rise of Apps Culture. Pew Internet and American Life Project, 1-46.

Re, A.M, Capodieci, A., Cornoldi, C. (2015). Effect of training focused on executive functions (attention, inhibition, and working memory) in preschoolers exhibiting ADHD symptoms. Fron tiers in Psychology, 6:1161.

Rueda, M. R., Checa, P., \& Combita, L. M. (2012). Enhanced efficiency of the executive attention network after training in preschool children: Immediate changes and effects after two months. Developmental Cognitive Neuroscience, 2(Suppl 1), S192-S204.

Thorell, L. B., Lindqvist, S., Bergman Nutley, S., Bohlin, G., \& Klingberg, T. (2009). Training and transfer effects of executive functions in preschool children. Developmental Science, 12(1), 106-113.

Traverso, L., Viterbori, P., \& Usai, M.C. (2015). Improving executive function in childhood: evaluation of a training intervention for 5-year-old children. Frontiers in Psychology, 6:525, $1-14$.

Vavoula, G., \& Karagiannidis, C. (2005). Designing mobile learning $\quad$ experiences. $\quad$ In $\quad$ P. Bozanis, \& E. N. Houstis (Eds.), PCI 2005, $\quad$ LNCS 3746 (pp. 534-544). Berlin: Springer-Verlag.

Vissers, C., Koolen, S., Hermans, D., Scheper, A., \& Knoors, H. (2015). Executive $\quad$ functioning in preschoolers with specific language impairment. Frontiers in Psychology, 6, 1574.

Wiebe, S., Scheffield, T., Nelson, J. M., Clark, C. A., Chevalier, N., \& Espy, K. (2011). The structure of executive function in 3-year-olds. Journal of Experimental Child Psychology, 108(3), 436-452. 